\title{
Overcrowding and Its Effects on the Social and Spatial Aspects of the Urban Fabric. The Case of Jabal Al-Natheef, Amman, Jordan
}

\author{
Raed AL TAL ${ }^{1}$, Rama AL MULQI', Lubna ALAWNEH' ${ }^{1}$, Saba TARAWNEH' \\ German Jordanian University, School of Architecture and Built Environment, Department of Architecture and Interior Architecture, \\ Amman, JORDAN \\ E-mail: raedaltal@yahoo.com, r-emulqi@hotmail.com, alawneh.lubna@gmail.com, saba.tarawneh@hotmail.com \\ DOI: 10.24193/JSSP.2018.1.03 \\ https://doi.org/10.24193/JSSP.2018.1.03
}

K e y w o r d s: Jordan, Jabal Al-Natheef, occupancy density, spatial density, spatial impact, social impact

\begin{abstract}
A B S T RA C T
This research examines the effects of overcrowding on social and spatial patterns of Jabal Al-Natheef in Amman, the capital of Jordan. It mainly tackles the concept of overcrowding, whether Jabal Al-Natheef is an overcrowded neighborhood or not, and how it affects the spatial morphology and the social behavior in this neighborhood. The study focuses on socio-economic aspects and housing typology morphology to relate it to the concept of occupancy and spatial density. The expected outcome is to verify the hypothesis of overcrowding on Jabal Al-Natheef and its impact on space and people. In order to answer the research questions, the researchers analyzed Jabal Al-Natheef based on site visits, open-ended interviews, official documents, and previous studies conducted by national and international urban organizations. The analysis was conducted according to the definition of overcrowding and its indicators. This research can set a foundation of analyzing informal settlements in Jordan in a more social and spatial sense, rather than only analyzing the basic needs.
\end{abstract}

\section{INTRODUCTION}

Amman has been a city of refugees since its modern foundation in the mid-nineteenth century where strangers, no matter their origin, were protected. The city has absorbed wave after wave of refugees, most of who have stayed and settled [1].

The influx of thousands of Palestinian refugees to Amman in 1948 marked a turning point in the city's economic and social fabric, increasing Jordan's population from 500,000 to 1.5 million within two years, one-third of whom being Palestinian refugees. The second wave of 400,00o Palestinians came in 1967 , when Israel occupied the West Bank. According to the British geographer Jane Hacker (1960), these waves highly influenced the social and political transformation, and development issues of Amman, including those of land use, city growth, population densities, internal commercial structures, and residential differentiations [2].

In addition, Ala' Al-Hamarneh (2001) stated that "Amman was built on the pain of others" [3, p. 173]. According to the Jordanian Department of Statistics, the greatest concentration of Amman's population resides in the eastern part of the city which includes one large official Palestinian camp and several other neighborhoods with significant Palestinian population.

This study mainly focuses on one of these large neighborhoods, Jabal Al-Natheef. Jabal Al-Natheef is 
an urban neighborhood in the eastern part of Amman governorate's Ras Al-Ain district. It is one of the oldest neighborhoods in Amman, as well as the poorest of the four neighborhoods in Ras Al-Ain, and an out-product urban settlement which resulted from the influx of Palestinian refugees. Although the majority of its population comprises immigrant Palestinians who settled here after 1948, initially living in tents and shelters (the area was a temporary meeting point at the time, known as "Mohammad Amin" Camp), it is not an official Palestinian refugee camp. Therefore, the bulk of the inhabitants in the neighborhood are non-camp refugees.

This research mainly questions: Is this type of a dense and impermeable urban neighborhood overcrowded or not? Moreover, what is the impact of this overcrowding on its urban and social fabric? In order to examine the overcrowding and its impacts on Jabal Al-Natheef, two major aspects will be analyzed: the spatial density on the one hand, and the social density on the other. Based on these two aspects, the results will be compared with the standard overcrowding measures in order to find whether or not it is overcrowded. Once the hypothesis of overcrowding is proven, further analysis will be conducted to investigate the impact of the crowded neighborhood on the living space and its residents.

According to the World Health Organization, "overcrowding refers to the situation in which more people are living within a single dwelling than there is space for, so that movement is restricted, privacy secluded, hygiene impossible, rest and sleep difficult” [4].

Overcrowding can be measured according to various indicators such as persons / room, persons / house, households / building, buildings / area, and so on. In this paper, we refer to it as occupancy density. Occupancy density, as defined by Edward $\mathrm{Ng}$, is the number of inhabitants to the floor area of an individual "habitable unit" [5, p. 47]. There are multiple standards regarding the measures of overcrowding related to spatial density, which is the concentration of people and/or buildings within a definite geographical unit. In this paper, the researchers will design a set of indicators that are tailored to the case of Jabal Al-Natheef and appropriate to the available data.

\section{THEORY AND METHODOLOGY}

Theoretically speaking, refugee camps present the image of a small city, informally developed; housing units are systematically located on plots divided by narrow streets and paths. According to Alnajada et al. (2014), financially capable inhabitants of the camps have simply gone vertical in their units to manage space for their extending families, and building regulations were not taken into consideration in this expansion [6].
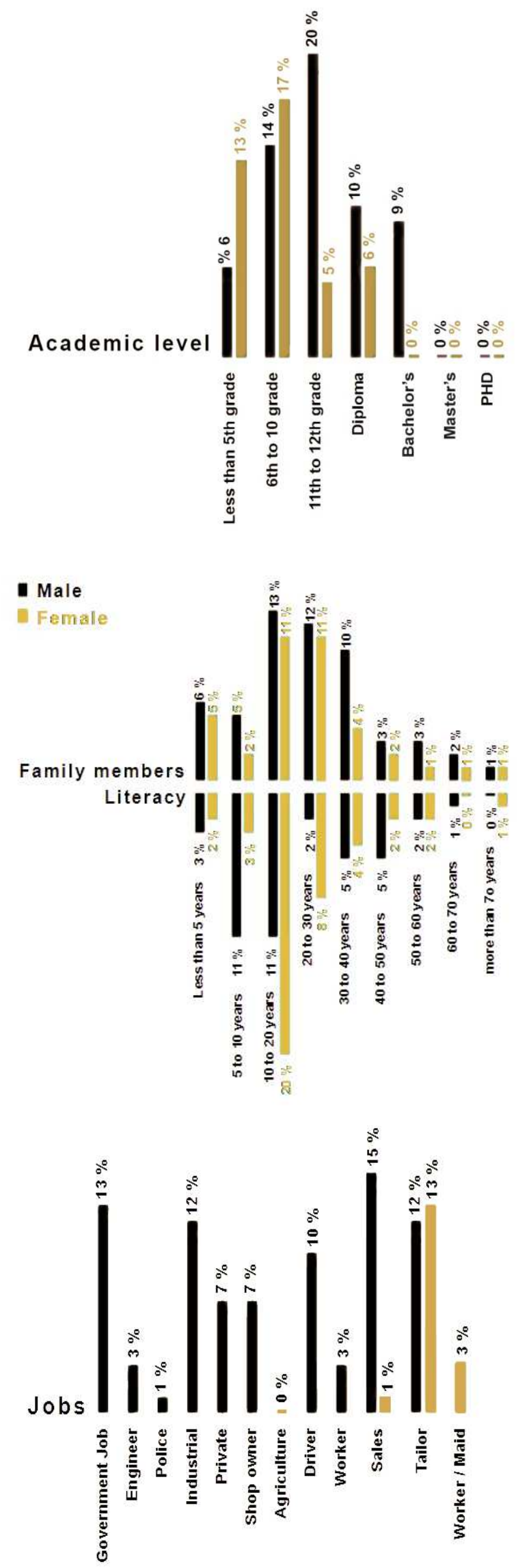
Natheef [6]. 
According to the Oxford Advanced Learner's Dictionary, an informal settlement is "a place where people decide to live and build temporary shelters, often followed by more permanent houses. Sometimes informal settlements are supplied with water, electricity, etc. and people can become owners of individual pieces of land" [7].

In Jordan, many refugees are not registered, and inhabitants in the informal Palestinian camps/neighborhoods like Jabal Al-Natheef are considered as Palestinian refugees, yet the zone is not officially registered as a Palestinian camp. Therefore, the Department of Palestinian Affairs does not maintain statistical or urban data regarding Jabal Al-Natheef. On the other hand, according to the Greater Amman Municipality, it is considered like any other urban neighborhood of the city; therefore, it is actually legally treated as an inhabited zone [6].

In short, Jabal Al-Natheef is a non-camp refugee settlement. Castells (1977) decided that there are urban drivers such as economic drivers, social or cultural drivers, and municipal or political drivers that influence the clustering and resettlement of refugees. Among these determinants, he considered the economic factor in causing clustering among immigrants as the most common determinant for the frequent location of immigrant quarters in certain low-income areas [8].

Economic indicators allow for the detection of peculiar structures when assessing the socioeconomic context in Jabal Al-Natheef. Many studies have analyzed the social and economic conditions of Jabal Al-Natheef to understand the effects of the poorly planned area on the residents, as shown in the statistics in Figure 1. As a community, Jabal Al-Natheef has common ethnic and geographic-based similarities related to their religion and Arabism; however, the subsiding diversity comes from the difference of their cultural backgrounds and traditions. Sandercock (1998) insists that more attention must be given to the sociocultural factors of the city as groups and individuals, of conflict and social polarization. Her point of view is that immigrant group's cluster for positive reasons, such as religion [9].

In this regard, community became a common understanding of a shared identity that relies more on the social processes of interaction and reciprocity operating within groups rather than boundaries of locality. In return Day G. and J. Murdoch (1993) state that "people's location within particular places tended to be an important aspect of their lived experience, what they might for example refer to as neighborhood" [10].

Then for Day G. and J. Murdoch (1993) community "had been a concept, which contained referees to both the importance of place, and the wholeness of social life, often formulated in terms of discrete ways of life" [10, p. 83], as in Jabal Al-Natheef.
This community suffers from different problems related to social aspects that are divided into three sectors: social infrastructure (health, education); social structure; and social behavior. The main reasons for these problems are poverty, high density, traditions, and a high unemployment rate [6].

Income sources in Jabal Al-Natheef are the typically public and private employment for monthly salaries, and small businesses. This implies having a set establishment or system that can churn out money for individuals such as privately owned shops, retirement income, and handicrafts. Unskilled workers generally concentrate in such areas, especially when they need to live as near to their sources of employment as possible. Moreover, long hours of work demand proximity to their homes and ease of access to markets, which causes an extra high spatial density in the commercial parts of such settlements [8].

One of the most important aspects regarding Jabal Al-Natheef is land ownership; residence is on privately owned land that is rented by the governorate for 99 years. Yet urban growth took place and developed like any other formal camp, but without any supervision or planning. Although the landownership is very complex in Jabal Al-Natheef, and the conditions are very hard, the price of the real estate is very high. The rents are extremely high compared to the low income per families, which is JD150-300 (\$200-600), which forms $56 \%$ of the monthly income for the family or one of the family members [6].

\subsection{Methodology}

This research consisted of both quantitative and qualitative data in order to verify the study. The starting point was the hypothesis: Is Jabal Al-Natheef an overcrowded neighborhood or not? The quantitative data was through pre-existing studies from two main resources: Alnajada et al. (2014), and the GJU urban regeneration study of Tarawneh et al. (2014).

The qualitative data was collected through interviews with residents, analyzing local newspapers and the above-mentioned studies. After the data collection, a full social and spatial analysis was conducted by the researchers in order to verify the hypothesis. Afterward, another analysis of the effects of overcrowding was conducted at both the social and spatial level, which will lead to a conclusion on the effects of overcrowding on the socio-spatial layers of Jabal Al-Natheef, as you can see in Figure 2.

To implement the primary purpose of this study within the research's themes, composite measure technique will be employed to determine the relationship between urban and occupancy density and international standards, and then see to what extent indexing physical and social - urban forms - Jabal AlNatheef is overcrowded. 


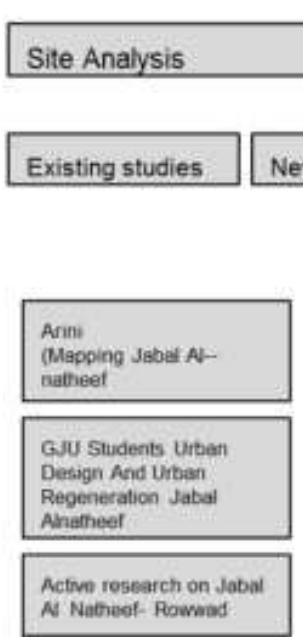

Fig.2. Methodology mapping.

\section{RESULTS AND DISCUSSION}

\subsection{Analysis layers}

As mentioned in the introduction, Jabal AlNatheef is a very complex neighborhood since it was developed organically as an informal camp without any planning control. This informal development has led to the creation of certain situations that affect the inhabitants' density. According to Galle (1979) most studies that tackled determinants of the "resettlement phenomenon" discussed social factors such as having family members nearby, in addition to political/municipal factors such as pushing people towards serviced areas [12]. In Jabal Al-Natheef, the social structure is homogeneous, as the majority of current residents descend from similar roots back in Palestine which stems from similar causes and makes it easier to study overcrowding due to similar characteristics. Yet, the neighborhood's over-density creates a harshly built environment, which will be discussed in the next sections.

\subsection{Space morphology and the spatial dimension}

Rofe (1995) states that theories of urban form revisit the questions of urban and neighborhood forms. These questions tackle the social meaning of a neighborhood; relations between them and to the city as a whole; functions they fulfill in the lives of individuals and in the life of the city; and finally, if the physical form of the city affects the formation of neighborhood and the quality of its life [13]. As revealed by Amman growth maps, Jabal Al-Natheef is one of the old neighborhoods as shown in Figure 3. However, it has grown very randomly and there is no clear network of infrastructure and streets.
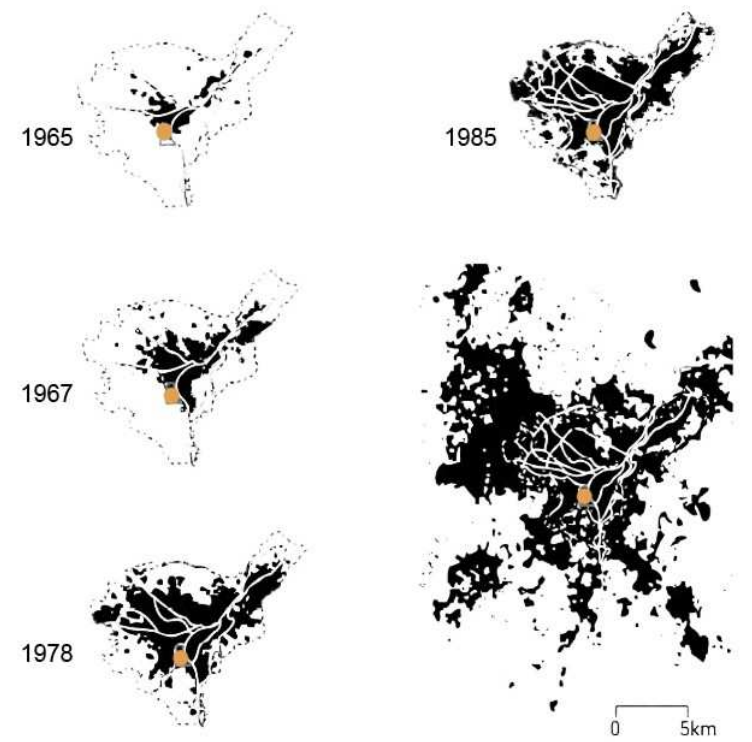

Fig. 3. Amman Development Plan [11].

One of the most pressing urban problems of the unplanned urban fabric of Jabal Al-Natheef is the housing congestion that poses a challenge for the types and quality of services. As for external services, there is an availability of services on the outer boundaries of the neighborhood and relatively convenient accessibility for residents. On the other hand, the neighborhood lacks the most basic inbound services because of its irregular and haphazard narrow roads and paths (For example, ambulances and cleaning vehicles cannot enter the neighborhood because of this haphazard layout, which, in return, causes hygienic and health problems (see Fig. 4). 

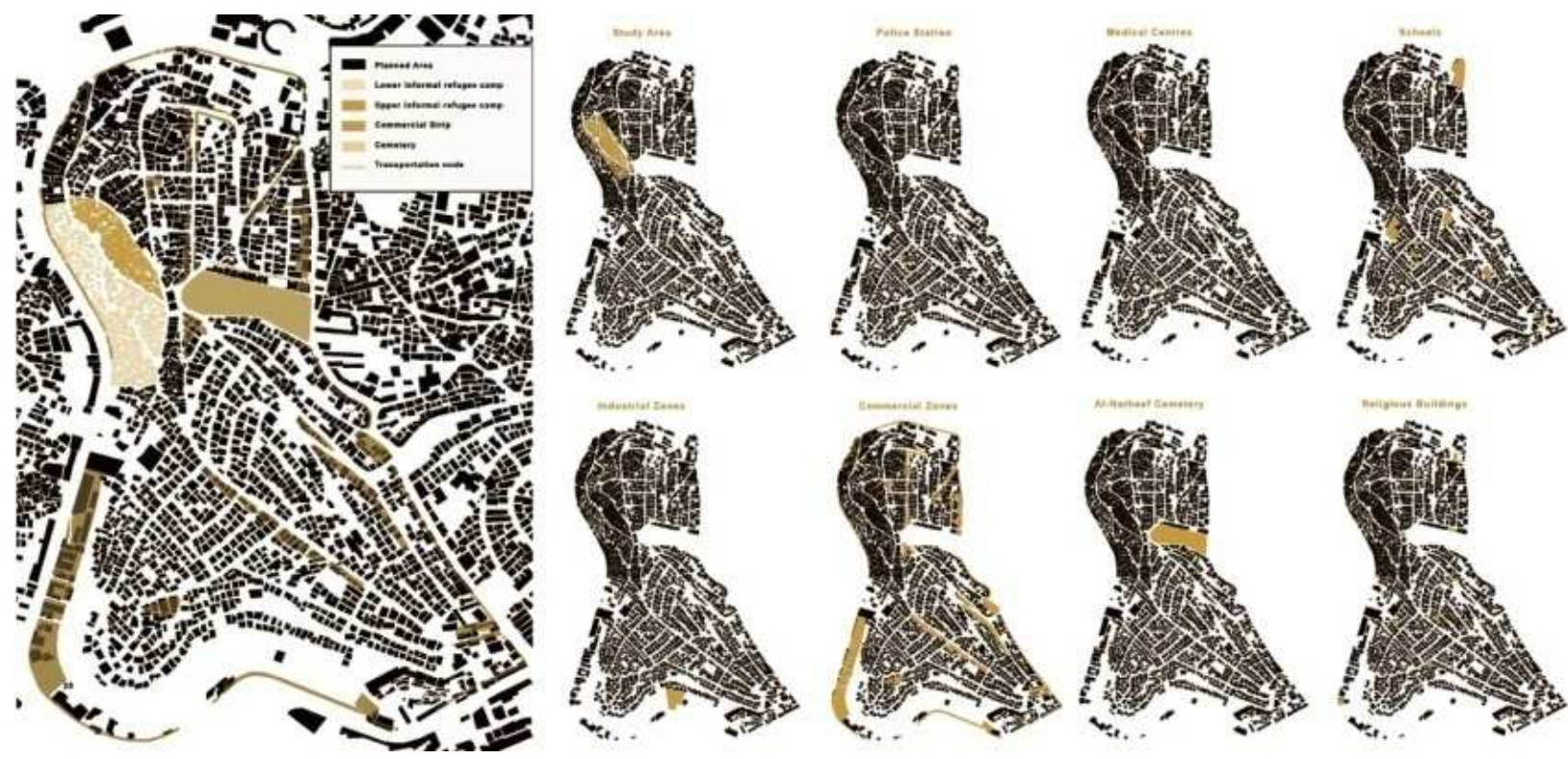

Fig. 4. Land use in Jabal Al-Natheef [6].

Table 1. Spatial density in Jabal Al-Natheef and ideal case.

\begin{tabular}{l|ccccc}
\multicolumn{1}{c|}{ Indicator } & $\begin{array}{c}\text { Residential } \\
(\boldsymbol{\%})\end{array}$ & $\begin{array}{c}\text { Commercial } \\
(\boldsymbol{\%})\end{array}$ & $\begin{array}{c}\text { Streets } \\
(\boldsymbol{\%})\end{array}$ & $\begin{array}{c}\text { Public space } \\
(\boldsymbol{\%})\end{array}$ & $\begin{array}{c}\text { Services } \\
(\boldsymbol{\%})\end{array}$ \\
\hline Standard Ratio & $40-50$ & $5-10$ & $20-25$ & $5-10$ & $15-20$ \\
Jabal Al-Natheef camp & 80 & $<1$ & 17 & $<1$ & $<1$ in the area study
\end{tabular}

Table 1 shows that over $82 \%$ of the land in Jabal Al-Natheef is built-up area which, according to the international zoning standards, is very high.

\subsection{Social dimension}

As mentioned in the literature review, Jabal Al-Natheef is a very dense and complicated neighborhood since it is an informal settlement that developed spontaneously, without any planning control. This informal development led to the creation of certain conditions that affect the inhabitants' behavior. On the one hand, the social structure of the camp is homogeneous, as most current residents descend from similar roots back in Palestine, which, stemming from similar causes makes it easier to study overcrowding due to similar characteristics. According Boal (1978), clustering helps in the consolidation of social cohesion. He describes one of the aspects of the ethnic cluster as "haven" - a place that the minority can use as a port of entry [14]. At the same time, Jabal Al-Natheef is neither socially nor spatially segregated from the city of Amman. In addition to the cultural similarities and strong social ties, such communities try to avoid isolation from the host society, which might prevent them from benefiting from full functional integration into society. It is a pattern of settlement, which, in
Castells' terms, is a "concentration without segregation" [8].

On the other hand, the urban density of Jabal $\mathrm{Al}-\mathrm{Natheef}$ is 69,269 person $/ \mathrm{km}^{2}$, which is very high in comparison with the urban density of Amman, which is 528.8 person $/ \mathrm{km}^{2}$. The total population of 54,000 persons resides on $0.078 \mathrm{~km}^{2}$. The total number of households in the neighborhood is 8,438 , and the average household size is 6.5 (Fig. 5).

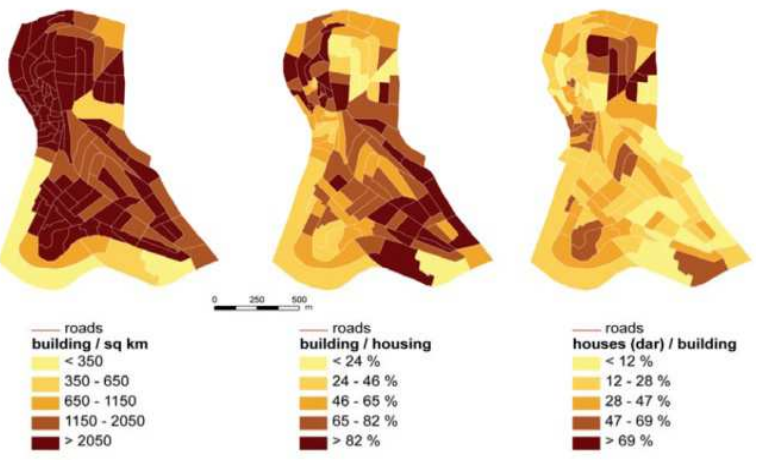

Fig. 5. Types of housing by blocks in Jabal Al-Natheef [6].

Due to this high density and social conditions of the inhabitants, there are neither single-dwelling nor villa residential houses in the neighborhood[15]. These numbers and ratios reflect the high urban density in 
Jabal Al-Natheef, which negatively causes social and behavioral problems. The residents' psychological response to this urban high density, as part of their feelings of being crowded, is that they lack privacy, and this in return increases undesired social interactions. As mentioned before, the lack of previous studies regarding the psychological strains of a harsh-built environment in the neighborhood will provide suggestions for future recommendations.

The majority of the building typologies are apartment buildings that were constructed and expanded on in several stages over time, according to the extended family's social needs. Lack of planning and the unorganized development of the residential buildings led to the development of clusters of housing units with minimal circulation space, which consequently causes deprivation in privacy within each housing unit. This means that there is overcrowding at the neighborhood level.

Regarding house-level occupancy density, the average area of the apartments in Jabal Al-Natheef is $88 \mathrm{~m}^{2}$. In return, and according to British standards, a household with six people should have at least10om ${ }^{2}$ of living space. The average bedroom area in Jabal AlNatheef is $15 \mathrm{~m}^{2}$, while the average number of rooms in its houses is three bedrooms. Taking that into consideration, the ratio of person/bedroom in Jabal AlNatheef is 2.3 persons/bedroom. This does not include a master or private bedroom for parents. According to a survey conducted by Alnajada et al. (2014), 53\% of parents share bedrooms with their children [6]. Bedroom areas form a small portion compared to the total area of the household. This could be due to rooted cultural traditions of the importance of the guestroom which is $1 / 4$ of the total area of the house as a reflection of the belief that hospitality is more important than having a spacious bedroom. According to British standards, the total bedroom area for a household with 6-7 people should not be less that $75 \mathrm{~m}^{2}$ [16], while the case here is $45 \mathrm{~m}^{2}$.

The Built Environment Deprivation Indicator index in Egypt provides the range of crowding rates (persons per room) based on different dwellings and household scenarios [17]. The current situation in Jabal $\mathrm{Al}$-Natheef camp is 2.3 persons in three rooms while the moderate situation and not ideal is 1.5 person in three rooms as shown in Table 2. As we see, all indicators of whether the urban density, person/room, bedroom area/person or house area/person indicate that the social fabric in Jabal Al-Natheef is overcrowded.

Table 2. Social densityin Jabal Al-Natheef and ideal case.

\begin{tabular}{|c|c|c|c|c|c|}
\hline Indicator & Urban density & Urban growth & Person/room & $\begin{array}{c}\text { Bedroom } \\
\text { area/person }\end{array}$ & $\begin{array}{l}\text { Households } \\
\text { area/person }\end{array}$ \\
\hline Standard Ratio & $\begin{array}{l}\text { Amman density } \\
528.8 \mathrm{per} / \mathrm{km}^{2}\end{array}$ & Vertical - planned & $1-1.5$ & $\begin{array}{l}\text { For } 6 \text { persons } \\
72 \mathrm{~m}^{2} \text { England }\end{array}$ & $\begin{array}{c}\text { For } 6 \text { persons Min } \\
100 \mathrm{~m}^{2} \text { England }\end{array}$ \\
\hline $\begin{array}{l}\text { Jabal Al-Natheef } \\
\text { camp }\end{array}$ & $69.269 \mathrm{per} / \mathrm{km}^{2}$ & $\begin{array}{l}\text { Vertical - } \\
\text { unplanned }\end{array}$ & 2 & $\begin{array}{l}\text { For } 6 \text { persons } \\
\qquad 45 \mathrm{~m}^{2}\end{array}$ & $\begin{array}{l}\text { For } 6 \text { persons Min } \\
\qquad 88 \mathrm{~m}^{2}\end{array}$ \\
\hline
\end{tabular}

The next section will show the effect of overcrowding on the spatial and social dimensions in the neighborhood.

\subsection{Effects of overcrowding: The spatial dimension}

Spatially, overcrowding, with a lack of preplanning and self-construction has caused irregular and multiple typologies of housing as shown in Figure 6 . The growth of housing in Jabal Al-Natheef started horizontally in 1980 until all vacant spaces were built on; they then proceeded in spreading vertically. Additionally, overcrowding with the absence of open spaces and clustered houses led users to use courtyards, rooftops and staircases as public spaces, because they provide a high level of privacy, safety and social relations.

Therefore, these spaces were divided into specific zones, based on the type of activities organized. These activities, on the other hand are determined by the relationships that exist among the inhabitants. An example is the Tomali Complex in Jabal Al Natheef, as shown in Figure 7, which contains the highest number of social activities because of the good relationships among the Tomali family members.

Moreover, pavement and staircases in these residual spaces were only built during the last decade; they are less than 1 meter wide and provide the only medium of movement in, out, and through camp. The overcrowding and vertical growth of buildings cause both negative and positive effects. On one hand, according to Alison (1961), these tight pathways, as shown in Figure 8, usually cause problems of hygiene, ventilation, lighting and waste [18]. In addition, difficulties exist in accessibility for ambulances, firefighting, and police. Furthermore, the infrastructure is inadequate.

On the other hand, these stairways and paths have become some of the most vibrant areas in the neighborhood because they are used as public spaces, especially by children and women. In her noncorrespondence paradigm, Jane Jacobs (1961) states that a neighborhood street serves the purposes of basic 
Overcrowding and Its Effects on the Social and Spatial Aspects of the Urban Fabric.

The Case of Jabal Al-Natheef, Amman, Jordan

Journal Settlements and Spatial Planning, vol. 9, no. 1 (2018) 25-33

safety and socialization at the street level. Moreover, they can be viewed as transition spaces which have their
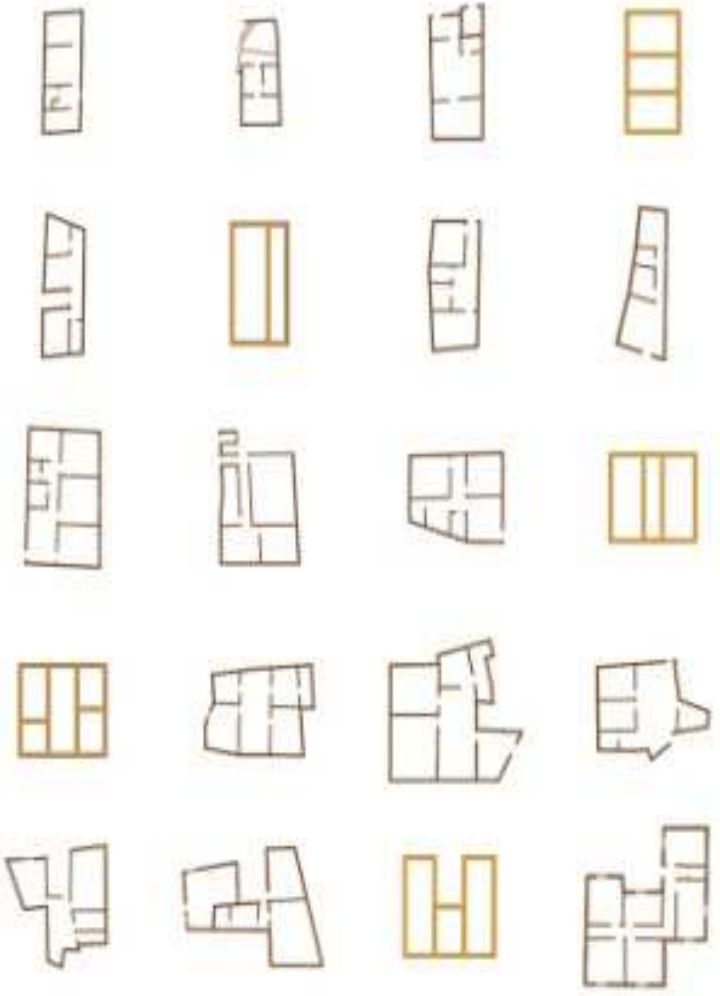

Fig. 6. Housing typology of Jabal Al-Natheef [6].

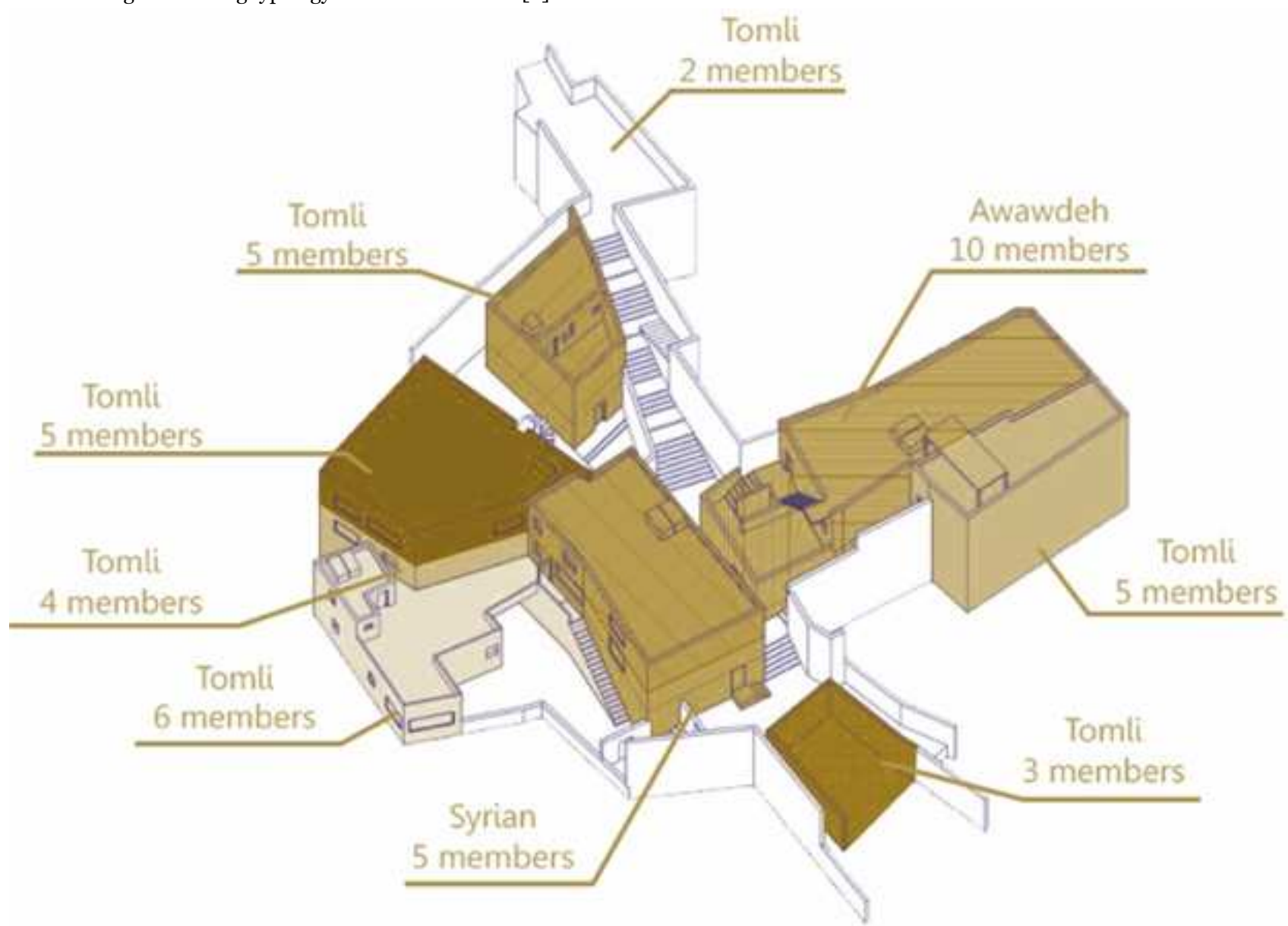




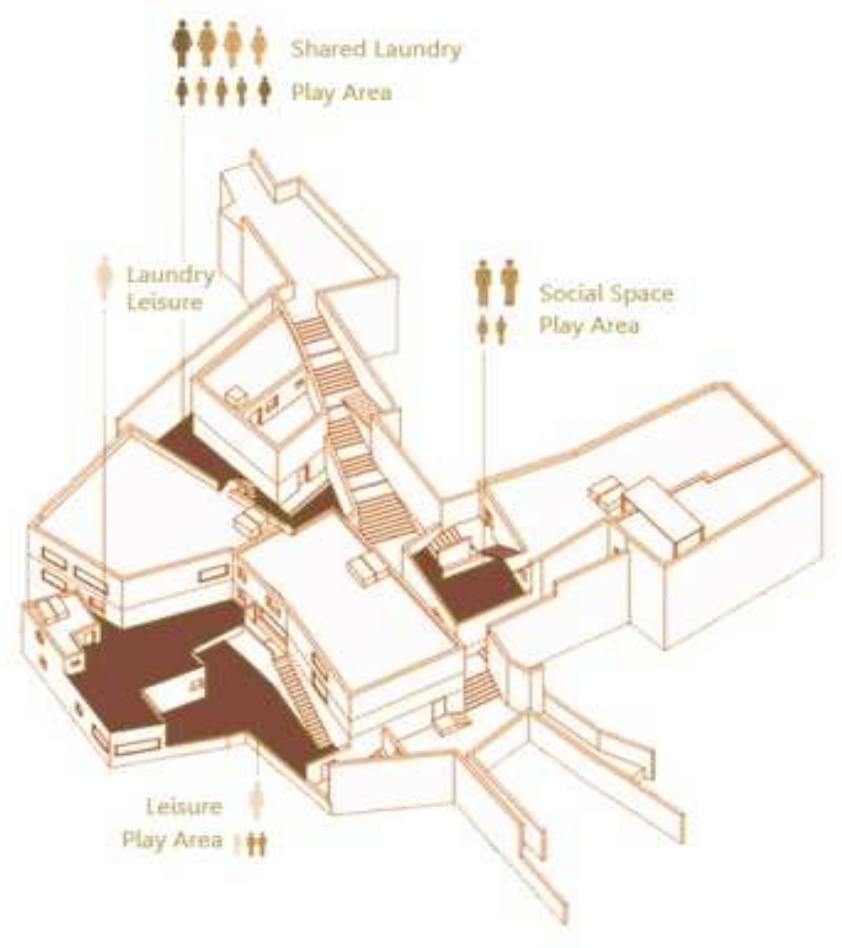

Piplitip Play Area

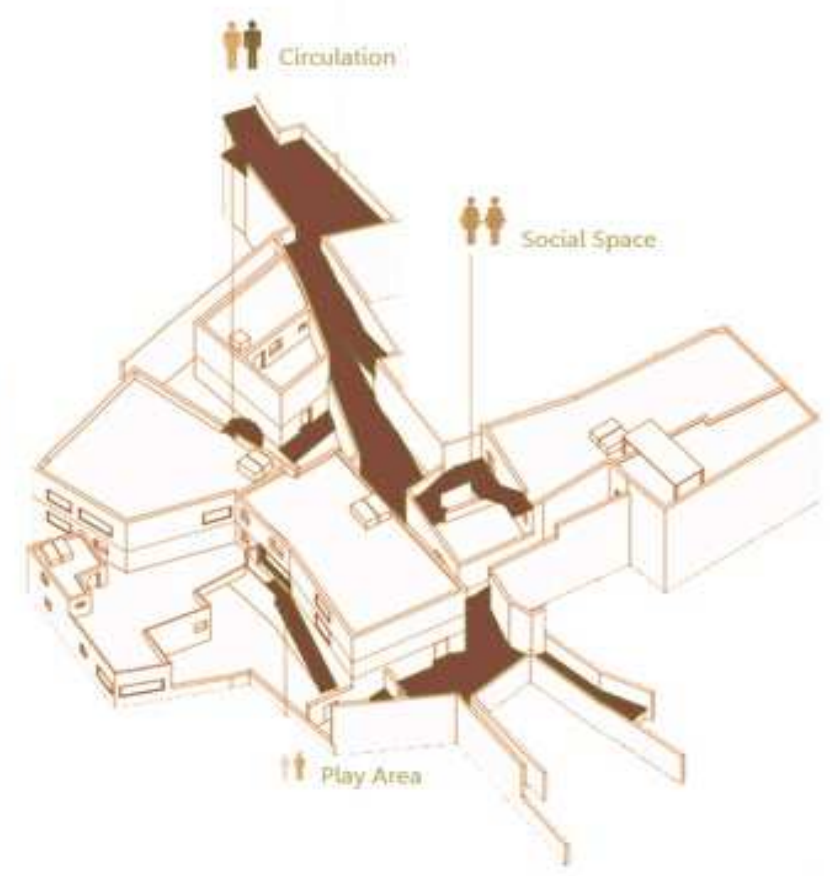

Fig. 7. Tomali Complexin Jabal Al Natheef [6].

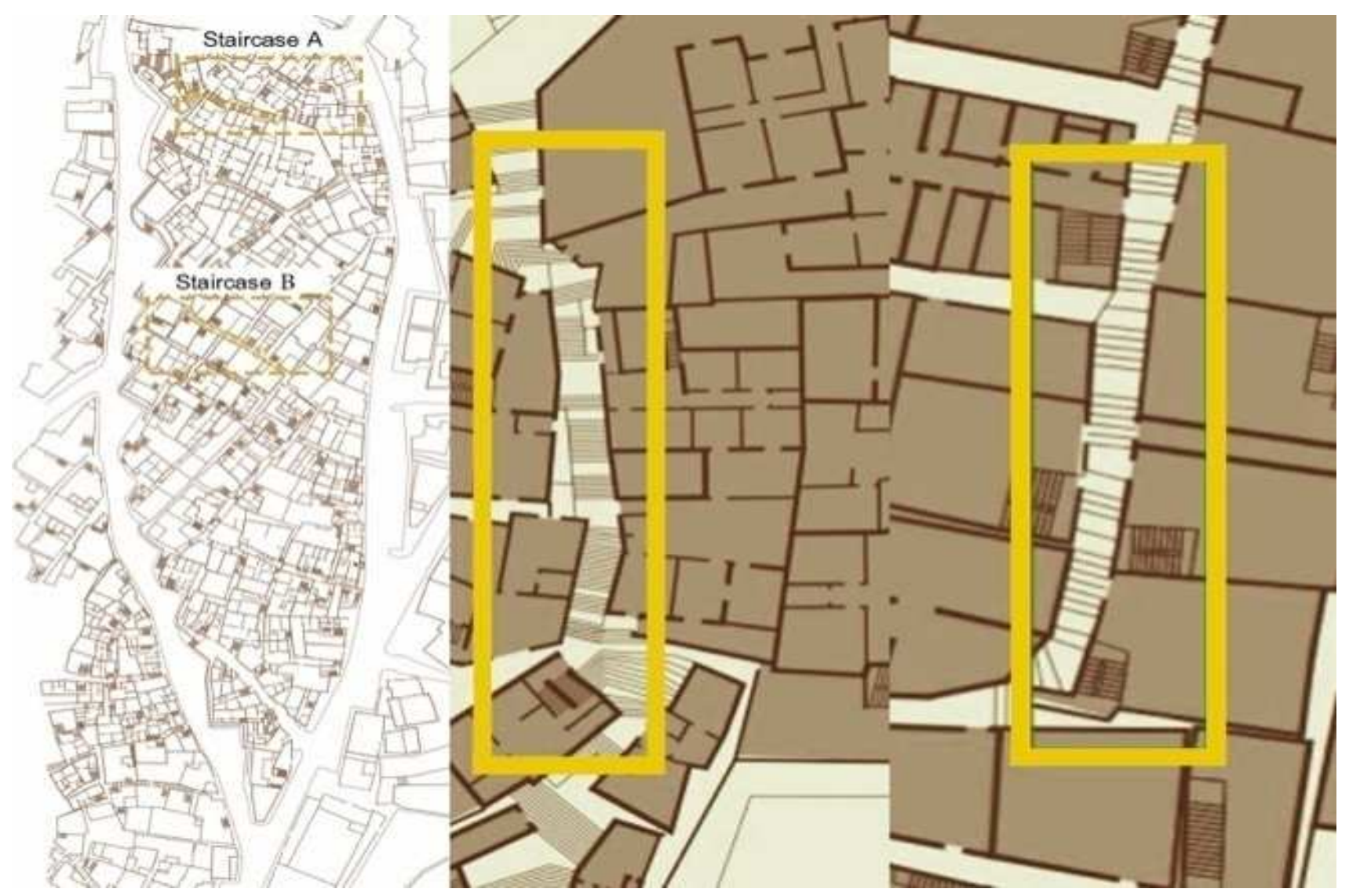

Fig. 8. Staircases in Jabal Al Natheef [6].

Yet, there are negative impacts of spatial overcrowding in Jabal Al-Natheef on social behavior, 32 which have created an unhealthy environment. One example is the existence of drug traffickers in the 
neighborhood. The absence of police stations makes it extremely hard for anyone to eradicate drug trafficking in the area. There has been domestic violence in the camp as well as urban violence because Jabal AlNatheef is known for its high poverty ratio. Children in each household have to contribute to the income of the house which leads to high rates of school dropouts; similar circumstances also lead to a high early-marriage rate within the area.

\section{CONCLUSION}

The analysis proves the hypothesis that Jabal Al-Natheef is an overcrowded neighborhood. This characteristic has several impacts on its spatial fabric, and, therefore, has left its impact on the social environment of its inhabitants. It is crucial for urbanists to become involved in similar cases of overcrowding in unofficial camps in Jordan's the residents may be subject to psychological and health issues. Although this neighborhood may have developed some positive attitudes towards its community through the years of its growth, there are still major negative impacts of overcrowding that must be addressed and solved. The researchers believe that policies and regulations should be developed to control growth and manage facilities in such areas. There also should be official standards for household capacities, as in developed countries, to control overcrowding situations and provide a decent way of living for every resident in the country.

At the academic level, the findings of this research will help to establish an urban assessment tool for testing the impact of conflict in overcrowded immigrant communities on the physical, as well as the social and cultural urban structure of multi-layered cities such as Amman.

\section{REFERENCES}

[1] Al Tal, R. (2006), Structures of authority: A sociopolitical account of architectural and urban programs in Amman-Jordan (1953-1999), Unpublished PhD Dissertation, State University of New York, USA.

[2] Hacker, J. (1959), Modern Amman: Social study, Durham College in the University of Durham, Durham, UK.

[3] Hamarneh, A. (2001), The social and political effects of transformation processes in Palestinian refugee camps in the Amman Metropolitan Area (1989-99). In: Joffé, G. [editor] Jordan in Transition 1990-2000, Palgrave Macmillan, New York City, NY, USA, pp. 172-190.

[4] Charts Bin (n.d.), Overcrowded Homes by Country. Retrieved from http://chartsbin.com/view $/ 42112$

[5] Ng, E. (Ed.) (2010), Designing high-density cities for social and environmental sustainability, Earthscan, London.

[6] Alnajada, H., AlJabi, L., Jabi, M. (2014), Mapping Jabal Al Natheef. Jordan Available at: http://arini.org/mapping-jabal-al-natheef publication Last accessed: November, 24, 2017.

[7] Oxford University Press, Available online at: https://www.oxfordlearnersdictionaries.com/definition /english/informal-settlement?q=informal+settlement Last accessed: March 23, 2018.

[8] Castells, M. (1977), The urban question: A Marxist approach, MIT Press, Cambridge, MA, USA.

[9] Sandercock, L. (Ed.) (1998), Making the invisible visible: A multi-cultural planning history, University of California Press, Los Angeles, CA, USA.

[10] Day, G., Murdoch, J. (1993), Locality and community: coming to terms with the place, The Sociological Review, 41, 82-111.

[11] Tarawneh, S., Zeidan, A., Samarah, A., AlBadri, S., Al-Ghaffari, M. (2014), Jabal Al- Natheef - Urban Design and Urban Regeneration. Unpublished report. German Jordanian University.

[12] Galle, O., Gove, W. (1978), Overcrowding, isolation, and human behavior: Exploring the extremes in population distribution. In Taeuber, K.E., Bumpass, L. L., Sweet, J. A. [editors] Social Demography, Academic Press, New York City, NY, USA, pp. 95-132).

[13] Rofe, Y. (1995), Space and community - the spatial foundation of urban neighbourhoods. In: Berkeley Planning Journal, vol. 10, pp. 107-125. Available online at: https://cloudfront.escholarship.org /dist/prd/content/qt8691z2bp/qt8691z2bp.pdf?t=m7w 1eu

[14] Boal, F. (1978), Ethnic Residential Segregation in Social Areas in Cities: Processes, Patterns and Problems. In D. Herbert, \& R. Johnston (Eds.). London, Wiley.

[15] Ababsa, M. (2004), Jordan Atlas, IFPO, Jordan.

[16] Greater London Authority (2006), Housing Space Standards, London. https://www.london.gov.uk /sites/default/files/hatc_housing_space_standards_re port_for_gla_2006.pdf

[17] Tooba (2016), The Overcrowding index. The Built Environment Deprivation Indicator. September 2016. Available online at: http://1otooba.org/bedi/en.

[18] Alison, G. (2001), Definitions of Crowding and the Effects of Crowding on Health, Ministry of Social Policy, New Zealand.

[19] Jacobs, J. (1961), The death and life of great American cities: The failure of town planning, Random House, New York City, USA. 